\title{
Research on Quality Cost Model (QCM) based on Quality Improvement Procedure (QIP) in an Auto-factory
}

\author{
Fuli Zhou ${ }^{1 *}$, Xu Wang ${ }^{1,2^{*}}$, Shan Chen ${ }^{1}$, Yandong He ${ }^{1}$ and Lin Zhou ${ }^{1,3}$ \\ ${ }^{1}$ School of Mechanical Engineering, Chongqing University, Chongqing, China \\ ${ }^{2}$ State Key Laboratory of Mechanical Transmission, CQU, Chongqing, China \\ ${ }^{3}$ Department of Electrical, Electronic, and Information Engineering "Guglielmo \\ Marconi" (DEI), University of Bologna, Via Venezia, Cesena, Italy \\ deepbreath329@outlook.com,wx921@163.com
}

\begin{abstract}
With the implementation of continues quality improvement procedure $(Q I P)$ in Chinese self-brand automotive firms, the quality-related cost needs to be identified correspondingly. Quality cost math models could reveal the mathematical relationship between the quality level and quality cost which provides the possibility for research on the trade-off of these two conflicting objectives, as well as contribute to quality related cost reduction. The quality index during QIP is established via Pearson coefficient within warranty period, related quality cost is categorized to conformance and non-conformance cost on the basis of the PAF ingredient as well. Four traditional quality cost math models have been analyzed in this paper, and the regression analysis based on curve fitting process has been implemented for a self-brand automotive firm during its QIP. The results verify that the four quality cost models $(Q C M)$ show their excellent simulating performance, which can uncover the optimal quality level and target R/1000@3MIS guiding correct operations during its QIP. In addition, the most appropriate quality performance level index is aggregated and calculated by employing a subjective AHP method, which specifies the quality improvement target ad potential cost reduction value.
\end{abstract}

Keywords: quality cost model (QCM), R/1000@3MIS, self-brand automotive firms, continuous quality improvement procedure (CQIP)

\section{Introduction}

Improving product quality has been wildly recognized as the best way to improve customer satisfaction, which can be realized by quality management practice during the entire life-cycle (LC) [1]. Recently the continuous quality improvement procedure (CQIP) has been proposed in self-brand automotive firms to promote its quality performance [2]. CQIP's implementation must take the cost related to quality activities into account, because the aim of quality improvement is not only to improve the ability for meeting client's requirement but also to minimize the cost paid for the effort. The competitive strategy for self-brand automotive firms is towards quality-oriented with lower cost, instead of discounted cost-oriented strategy [2,3]. The prerequisite of the QIP practice is that the profit of quality advancement must have the overwhelmed advantage than cost investment for QIP activities. Therefore it is of high urgency for maintenance cost consideration in post-market and trade-off between quality performance and quality cost. The widely accepted definition of quality cost (called cost of quality as well, CQO), according to Dale and Plunkett, is the expenditure incurred in the design, implementation, operation and maintenance of a quality management system, besides including the cost of resources committed to continuous improvement, the costs of system, product and service failures, and all other necessary costs and non-value added activities required to achieve a quality product or service [3]. This concept and quality cost model have provided a 
solution to reflect the economics of QIP. In other words, it can present the relationship between quality and cost, which definitely makes significant guidance for automotive firms. There are mainly three kinds of researches for fresh quality cost study, that is, COQ definition \& category, quality cost measurement and models in each organizations. Researches of quality cost are developed on the basis of the contribution by Feigenbaum, Juran, Crosby and Freman [4-6].

There are plenty of quality cost measurement framework, and the preventionappraisal-failure (PAF) cost classification was the most prevailing consideration for quality cost, which has three main parts: prevention cost, appraisal cost and failure cost. The PAF classification has proved to be the most widely used in practice when quality cost is measured by companies [5, 7]. Besides, it has been regulated by federal standards, such as ASQC (US), ISO9004-1, and GB/T13339 (CN). Prevention cost is the cost of various activities specifically designed to avoid poor quality in products and services $[4$, 8]. Appraisal cost is the expenditure associated with measurement and testing, evaluating, or auditing products or services to assure conformance to quality standards and performance requirements. Failure cost is the inevitable fee that product or services cannot conform to customers' needs from the defective standpoint. In order to study the detail failure occurrence, failure cost has been divided into internal and external failure cost. No matter how the quality cost category is, all the qualitative classification can be regarded as the conformance cost (the cost that contributes to the high quality or customer satisfaction, like prevention \& appraisal cost) and non-conformance cost (the cost for rectification once the un-conformance or failure occurred, such as failure cost). These divisions of the traditional quality cost model are made on the basis of 'conformity' concept. They believe that with the constant improvement of the quality level, though the failure cost will be reduced, the enterprise must invest more to the assurance cost, which in other words to say that the investment cost and quality level show the positive correlation, but the failure cost will reversely change. Therefore, there must be a best equilibrium, when the quality cost and quality loss cost are equal, the quality of the corresponding level is the best quality level for the specific quality cost. The relationship between cost items and quality level in PAF model based on Juran's philosophy and zero defect principle is depicted as Figure 1 shows.
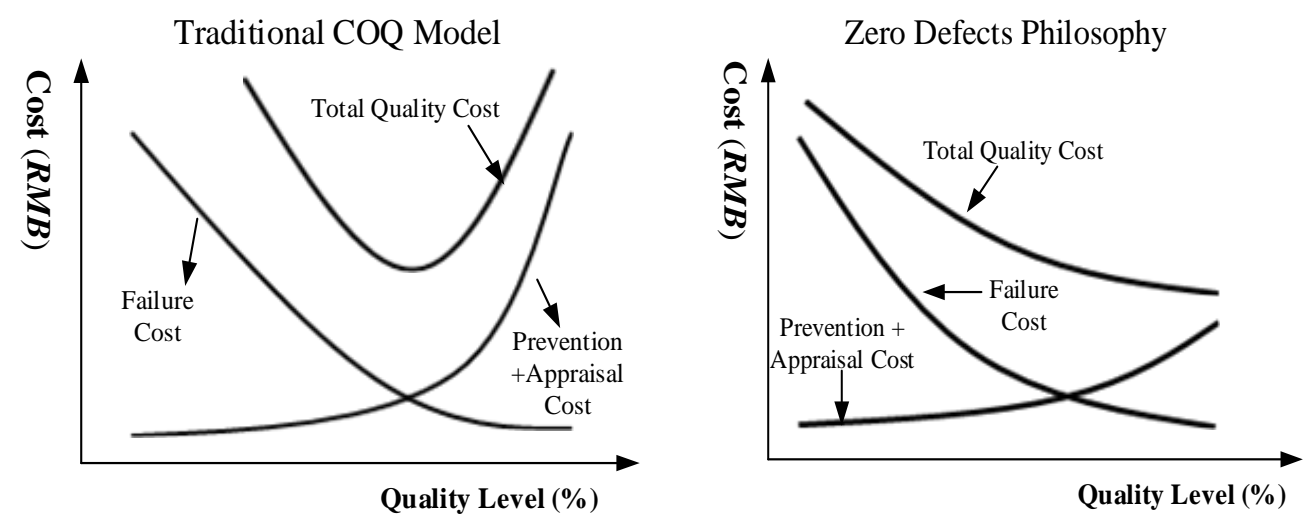

Figure 1. Quality Cost Models under Different Philosophies

As the figure illustrates, there is some difference for total quality cost based on two distinct philosophies, as well as prevention \& appraisal cost. Actually, the main discrepancy of these two is whether there is a soaring increase for P\&A cost, namely the effective input for quality advancement. The traditional PAF model through the optimal quality is a certain point away from perfect for shapely increasing for P\&A cost, while the zero defect philosophy claimed that no defectives come at minimum cost. There are any other definitions and quality cost models in the previous studies [4, 9-11], such as 
conformance + non-conformance proposed by Crosby, quality loss model based on Taguchi, and activity-based costing (ABC) method etc. Two dimensional quality cost model from the integration of procedure process and cost segment standpoints have been analyzed $[11,12]$, which has combined the ABC method and other COQ items. Similar to the COQ measurement, the life cycle cost (LCC) also has been integrated to provide the framework for recognizing estimated total incremental cost during QIP [13, 14]. The existing COQ model and the frequency of its utilization have been reviewed as table 1 manifest $[4,15]$.

For manufacturing industry, construction, and discrete production organizations etc., PAF category has been the most widely used [16-18]. Thus, the PAF category in this paper for self-brand automotive firms will have been studied, as well as COQ model research for trade-off between quality performance and monetary investment.

Table 1. General Quality Cost (QC) Models \& Category

\begin{tabular}{llll}
\hline NO & QC Model & Category & percentage \\
\hline 1 & PAF model & P+A+F (IF + EF) & $37 \%$ \\
2 & Crosby's models & $\begin{array}{l}\text { Conformance + Non } \\
\text { conformance }(\mathrm{C}+\mathrm{NC})\end{array}$ & $5 \%$ \\
3 & Intangible cost models & $\begin{array}{l}\text { P+A+F+Opportunity } \\
\text { C+NC+O+ Hidden }\end{array}$ & $21 \%$ \\
4 & Process cost models & $\begin{array}{l}\text { Conformance + Non } \\
\text { conformance }(\mathrm{C}+\mathrm{NC})\end{array}$ & $10 \%$ \\
5 & ABC method & $\begin{array}{l}\text { Value added + N-V } \\
\text { Quality loss + process } \\
\text { inefficiencies }\end{array}$ & $15 \%$ \\
\hline
\end{tabular}

This paper analyzed the quality parameter based on characteristics of automotive product and QIP. Quality cost segment distribution and quality improvement target during QIP can hardly have the uniform regular formula or function due to the discrepancies among all of industries. Thus research on the quality cost math model and quality improvement target identification for the automotive industry is an emergency for the implementation of CQIP for these days, especially for self-brand vehicle firms. The remainder of this paper is structured as follows. In next section, the driven power of product evolution and quality improvement based on QIP practice in self-brand vehicle firm has been investigated. The parameter R/1000@3MIS that reflects vehicle quality level has been selected by correlation analysis owing to the hysteresis of vehicle quality responsiveness, as well as the CQIP process in section 2 as well. Traditional four QC math models have been investigated, and regression analysis is utilized to verify the quality cost model in the subsequent section. A case study in a self-brand automotive firm has been conducted to verify in the section 4 . We close this paper with findings and conclusions at last.

\section{Quality Improvement Procedure (QIP)}

\subsection{Quality improvement Procedure in Self-brand Automotive Firms}

There are many activities have been involved in the whole process for the formation of automotive product, and the most important procedures for self-brand vehicle firms in China are stamping, welding, coating and final assembly.

As for Chinese automotive enterprises, their competitive strategy being altered towards high product performance with excellent quality and rational total cost from whole lifecycle, instead of low cost competitive ad-vantage at their infancy. According to the lifecycle theory, the quality \& performance of the final product can be improved and advanced due to capitalism investment in any quality controlling stage. From the 
development experience of automotive firms in China, it is wise to improve the quality of its product, most importantly, the total lifecycle cost or quality cost has decreased as well, due to the shapely decreased on un-satisfaction and non-conformance expenditure, which caters to the Aurora's research in food industry. In addition, the customer satisfaction soared, which does good to the brand generation for self-brand automotive. It is that CQIP that stimulates the brand generation into a realization, whose evolution $\&$ advancement of vehicle products is as Figure 2 shows.

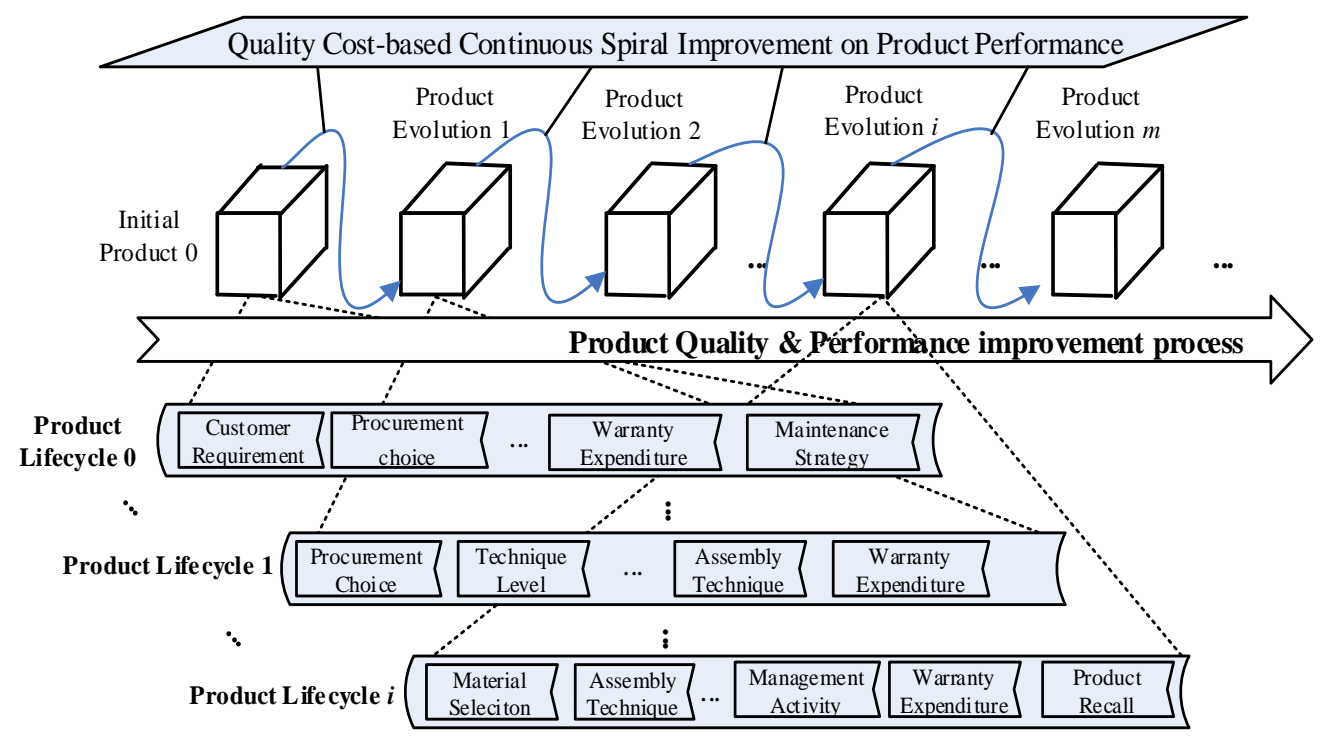

Figure 2. Quality Cost-based Product Performance Spiral Improvement

As for the total life-cycle characteristic for quality improvement practice, the improvement on any process could possibly make quality progress, for instance, material alternative, supplier improvement, technology skills, and quality training etc. While the responsibility of QIP team members is for diagnosing the problems of existing products, and putting forward solution for further improvement. The duty has determined that they must come from different departments including $\mathrm{R} \& \mathrm{D}$, procurement, manufacturing, and sales marketing etc. The improvement measures definitely make contributions to quality advancement, financial performance improvement, and customers' satisfaction, as well as the brand generation [7]. However, as we all know, it is unwise to blindly pursue the quality advancement with cost ignorance. As the product performance improved, conformance cost or prevention/appraisal cost definitely increased, consequently, nonconformance cost or failure cost may keep decreasing with the continuous investment on the front processes. However, quantitative cost items in COQ segments with different quality performance cannot be identified and recognized, which cannot provide accurate guidance during CQIP. Thus, the trade-off between of the quality level and cost \& benefit in automotive industry need to be identified and verified based on previous quality cost math model researches.

\subsection{Quality Index Analysis}

Due to the complexity and dynamic characteristic of automotive products, the long circle for problem feedback makes it hysteretic for QIP. The warranty time has been extended to 3 years since much attention has been paid to the after-sales market, with related legislation published by the Chinese government. The R/1000@XMIS term has been widely used by the engine firm to represent the quality and performance of automotive products, which reflect the failure frequency statistics in stochastic selection 
samples within X months after its delivery to users. It can directly reflect vehicles' quality performance for each generation, or even each batch, which is given by:

$$
R / 1000 @ X M I S=\frac{N_{X f}}{N_{X 0}} \times 1000
$$

Where, $N_{X f}$ is the frequency of failure occurrence, objects involve vehicles whose failure \& maintenance occurred within these $X$ months, as well as service time exceeding $X$ months. $N_{X 0}$ denotes the number of vehicle sample whose operation time has surpassed $\mathrm{X}$ months. $\mathrm{X}$ means time range called by month, and MIS is the shortage of months in service, which means the vehicle usage situation before its failure to scrap.

The unknown and uncertain factor the above index is $X(X=1,2 \ldots 36)$, which reflects the time period for problem feedback. As is well known, the more $X$ is, the more accurate and realistic information it can reveal, and vise visa. While, the smaller $X$ could make such firms do rapid response for quality issues. Therefore the determination of this quality index selection becomes crucial for this research. The best situation is to utilize the alternative one, that is, the R/1000@1MIS information which could accurately reveal or represent the R/1000@36MIS knowledge with the least time period for a quick response. In order to deal with this obstacle, coefficient analysis has been implemented to select the quality level representation according to Pearson Coefficient, which is given by:

$$
\rho=\operatorname{COR}(X, Y)=\frac{\operatorname{Cov}(X, Y)}{\sqrt{\operatorname{Var}(X) \cdot \operatorname{Var}(Y)}}
$$

Where, $\operatorname{Cov}(X, Y)$ is the covariance of two variables $X$ and $Y$, and $\operatorname{Var}(X) / \operatorname{Var}(Y)$ is its variance, respectively.

\subsection{Cost of Quality Category Analysis}

As we all know, cost data is always exists adhering to financial report forms, original certificate of all kinds and temporary report of organization, instead of category items based on quality cost classification. Many terms have been occurred in the quality cost field, such as quality-related cost, cost of quality and total life-cycle cost etc. There are two mostly used in typical quality cost categories that are PAF model and conformance plus non-conformance model. The cost segment unit divided by these two dimensions keeps similar, which is based on the basic operation activities (ABC method) due to the discrepant characteristics and procedures of different industries. The relationship and affiliation between these two cost classification and COQ items are as following Figure 3 shows.

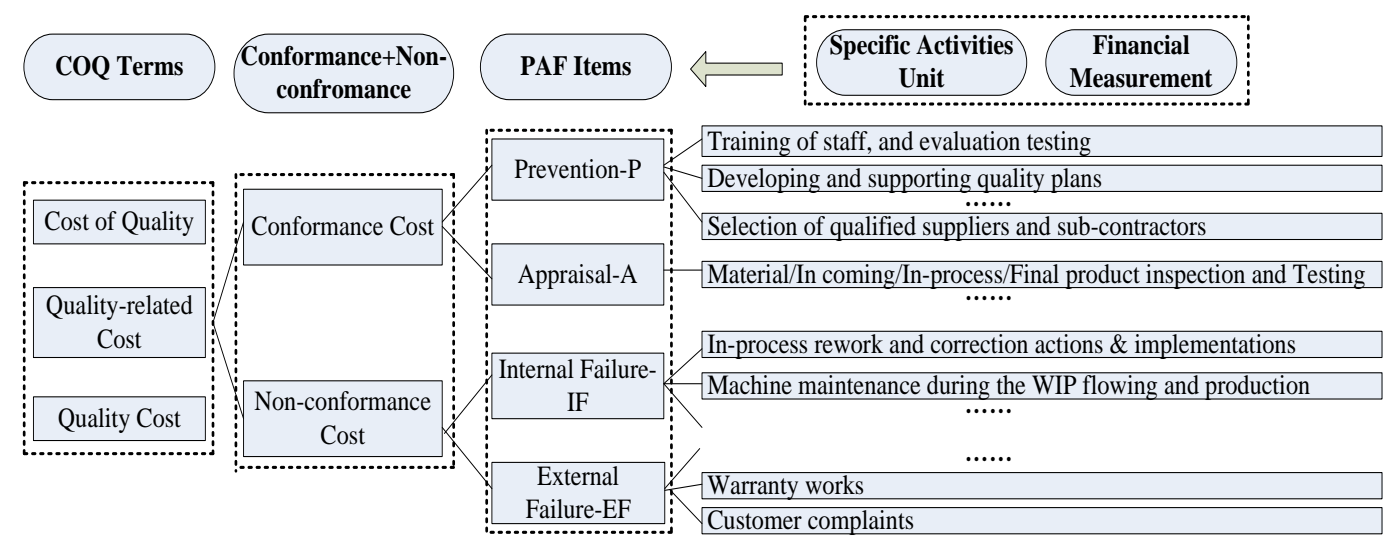

Figure 3. Two COQ Category and its Relationship 
The Figure 3 has illustrated the COQ terms and the two prevailing category model. In fact, the two categories can be transformed from a different standpoint, which has the similar cost unit measured by a particular activity.

\section{Quality Cost Math Models \& Methodology}

The qualitative analysis for QC model has been experienced for a long period development with a few quantitative analysis on relationships between quality cost and quality level. During the process of QIP in automotive organizations, the quality cost math model played a significant role on the capitalism investment determination and quality performance identification.

\subsection{Typical Quality Cost Math Models}

As abovementioned, there are huge amount of literatures has been focused on improved COQ model and its empirical study in various industries. Most of the literatures focused on the precise cost item calculation, instead of performing the specific mathematical model and empirical research. There are two kinds of research categories for COQ model, one is the quality cost study, which focused on the cost measurement and reporting systems establishment [16, 19-21], and the other is the specific optimization determination for certain industry based on the quality cost model analysis, no matter qualitative model or quantitatively functional model [22-24]. The aim of this paper is to verify and examine the specific QC math model for self-brand automotive industry based on typical quality cost functional type, which could give accurate guidance for engine firm during its QIP.

Quality cost math model is researched by Heravi and Aurora gives the optimal situation (the optimal conformance level or cost segments distribution) for the food industry and construction project respectively. While, both of them have made the curve fitting procedure according to the compile data by various prior distribution or polynomial, while this paper focused on the traditional quality cost model occurred in previous study, to identify the quality cost model in automotive industry during its QIP. The limited quality cost math model mainly consists of the four most common mathematical models: exponential function, Taguchi quality loss function, the Cobb Douglas production function and K. K. Govil model [25-27], which have been illustrated as Table 2 shows.

Table 2. The Four Typical Quality Cost Math Models

\begin{tabular}{llc}
\hline Function type & Targeted COQM model & NO. \\
\hline Exponential function (EF) & $\min L(\lambda)=L(\lambda)+A(\lambda)=a_{1} e^{-b_{1} \lambda}+a_{2} e^{b_{2} \lambda}$ \\
$\begin{array}{l}\text { Taguchi quality loss } \\
\text { function (QLF) }\end{array}$ & $\min W(\lambda)=A(\lambda)+L(\lambda)=a_{2} \lambda^{b_{2}}+\left[a_{1}+b_{1}(\lambda-1)^{2}\right]$ \\
$\begin{array}{l}\text { Cobb - Douglas production } \\
\text { function (CDF) }\end{array}$ & $\min W(\lambda)=L(\lambda)+A(\lambda)=a_{1} \lambda^{-\beta_{1}} e^{\varepsilon}+a_{2} \lambda^{\beta_{2}} e^{\varepsilon}$ \\
K. K. Govil model (KGM) & $\min W(\lambda)=L(\lambda)+A(\lambda)=F[(1-\lambda) / \lambda]^{G}+K[\lambda /(1-\lambda)]^{R}$
\end{tabular}

As is shown in the Table 2, there are four kinds of mathematical quality cost models to reflect trade-off between quality level $(\lambda)$ and quality cost. Four quality cost mathematical models have been generated by the combination of the conformance cost function and unconformance cost function, which are also can be regarded as the combination of prevention + appraisal cost function and failure cost function. These four models are all base on "compliance" quality. This concept believes that quality loss cost would decrease with the improving of the quality level, but it also needs to pay more to prevent and appraisal cost. And when the quality level tends to zero defect, companies must pay immeasurable cost of quality assurance, which recognized it non-economic. According to 
the basic shape of the COQ conceptual model in the first section, the cost item has the general formula with exponential function, power lower function and polynomial function, while the specific quality cost function only can be explored by the particular practice of the enterprise.

\subsection{Regression Analysis based on QC Math Models}

Regression analysis, for the first time applied into engineering, has been shown to be an effective method to depict the math relationship between two elements, which definitely provide guidance for organizations to further QIP activities. As the first phase of studying the optimum quality level, the prevention cost, appraisal cost and failure cost curves were plotted according to the compiled data. The non-linear regression analysis of the foundation of the four model format has been performed with comparison. The performance of four function forms was discussed by analyzing regression results, with combination of analyzing the graphic representation of each fitting function curve. Estimation for the parameters of the four QC math model has been implemented based on least squares method [28].

The performance of curve fitting for non-linear regression analysis can be reflected by $r_{N L}$ index, which is given by the following Eq. (7). According to Heravi [29], there are six stages for curve fitting procedure to implement the four QC model curve fitting in turn, each of which should be controlled by the performance index.

$$
r_{N L}=\frac{\sum\left(y_{i}-\bar{y}\right)\left(\hat{y}_{i}-\overline{\hat{y}}\right)}{\sqrt{\sum\left(y_{i}-\bar{y}\right)^{2} \sum\left(\hat{y}_{i}-\overline{\hat{y}}\right)^{2}}}
$$

\section{Case Study}

To verify the CQIP progress in the CA self-brand automotive firm, and to establish a QC math model for trade-off between quality level and cost, the data in CA organization has been collected and researched at first. CA AUTOMOBILE Co., Ltd was founded in 1862 , and it becomes one of the most famous self-brand automotive firms in China, who including mini-cars, cars, buses, trucks, SUV, MPV and other wide series products spectrum. As is known, CA was trying to shift its competitive strategy towards high quality, high technique with relatively low cost, instead of minibus production with cost superiority strategy. Therefore, CQIP has implemented in this organization for a long period with giving attention to quality-related cost accounting.

\subsection{Data Collection \& Pre-processing}

Failure \& maintenance data in different time period is collected about R/1000@XMIS $(X=1,2, \ldots, 6)$ knowledge, as well as the R/1000@36MIS information about vehicles sold since Jan 2012. Correlation analysis based on Bivariate process has been performed between 36MIS and each other criteria values. Pearson coefficients were calculated as Table 3 manifests, which can reveal that the 3MIS shows better performance with a relatively short time period, as well as the coefficient analysis between the quality level criteria R/1000@3MIS and 36MIS (Figure 4).

Table 3. Correlation analysis result

\begin{tabular}{lccccc}
\hline R/1000@XMIS & $\mathrm{X}=1$ & $\mathrm{X}=2$ & $\mathrm{X}=3$ & $\ldots$ & $\mathrm{X}=6$ \\
\hline Pearson Value & -.113 & 0.753 & 0.954 & $\ldots$ & 0.958 \\
Sig. & 0.592 & 0.436 & .000 & $\ldots$ & .000 \\
\hline
\end{tabular}




\begin{tabular}{llll}
\hline & & MIS3 & MIS36 \\
\hline \multirow{4}{*}{ MIS3 } & Pearson. & 1 & .954 \\
& Sig. & & .000 \\
& N & 25 & 25 \\
& Pearson & .954 & 1 \\
MIS36 & Sig. ${ }^{\circ}$ & .000 & \\
& N & 25 & 25 \\
\hline
\end{tabular}

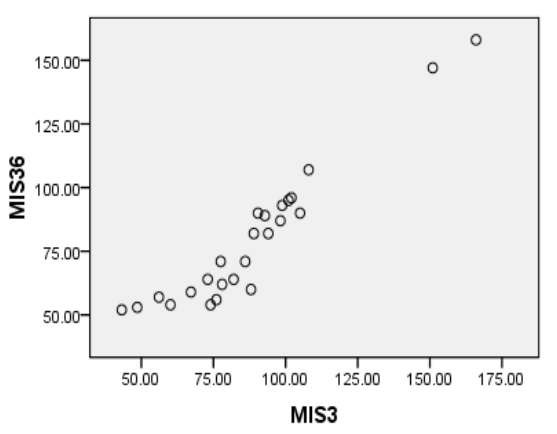

Figure 4. Coefficient analyses among R/1000@XMIS

As can be seen from the figure 5, the R/1000@3MIS shows its high consistency with the quality performance during the warranty period. The Pearson value between R/1000@3MIS and R/1000@3MIS is 0.954, which means the tendency of failure outcomes for these two discrepant periods presents high similarity. As we can see from table 4, optimal and shortest issues feedback time is " $X=3$ ", that is, R/1000@3MIS index, which can be recognized as the representative of quality level criteria for its quick response and high coherence. Therefore, the quality level information can be obtained from the global quality research system (GQRS), as well as the quality-related cost. The transfer formula between quality criteria $\lambda$ and R/1000@3MIS is given by Eq. (8). In order to perform curve fitting procedure, typical normalization operation with mum/minimum operator should be conducted, which makes the two variables belong to $(0,1)$.

$$
\lambda=F(R / 1000 @ 3 M I S)
$$

The vehicle failed is always due to its components or parts. Therefore, this case focuses on one of the key parts, rear shock absorbers, which has proven to be the crucial defensives by Pareto chart. The relationship between R/1000@3MIS and quality parameter $\lambda$ can be defined in the following Eq. (9) with serial-parallel components system structure into consideration.

$$
1-R=\sum_{i=1}^{2} C_{2}^{i} \lambda^{i}(1-\lambda)^{2-i}
$$

Where $\lambda$ is qualified rate per rear shock-absorber, and the R/1000@3MIS is the obtained value from GPRS. The function forms for cost items with quality level are given as following formula (10), which can be formed by previous four specific functional forms summarized above.

\subsection{Curve Fitting Procedure}

$$
Q C=A(\lambda)+L(\lambda)
$$

As previous studies claimed, the functional form of QC math model may vary for different industries, even for discrepant organizations. According to the previous criteria analysis, the corresponding quality cost data in each batch have been investigated, which can be the learning examples and evidence to make curve fitting process.

In order to catch up with QC math model, the quality cost items are defined as the dependent variable, while the quality level $(\lambda)$ is set as the independent one. The curve fitting procedure performed makes the graph showing four different functional connections between quality and cost. The function forms about $\mathrm{P}+\mathrm{A}(\mathrm{A}(\lambda))$, and failure cost $(\mathrm{L}(\lambda))$, as well as total quality cost, namely $\mathrm{A}(\lambda)+\mathrm{L}(\lambda)$ are investigated, whose independent variables are quality level $\lambda$. 


\subsection{COQ Model Results}

According to the practical data of rear shock-absorber investigated in CA L.td, curve fitting procedure has been launched based on the four theoretical QC math models. The functional relationship between these two elements can be visualized by function curves presented in Figure 5 as well.

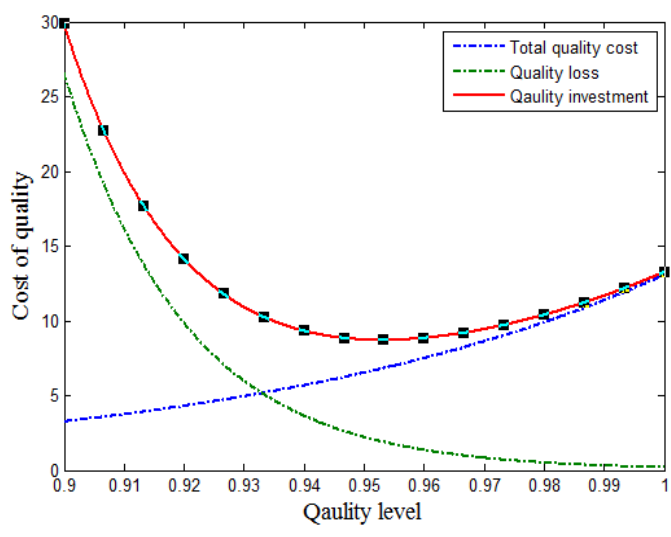

(a) EF Math Model

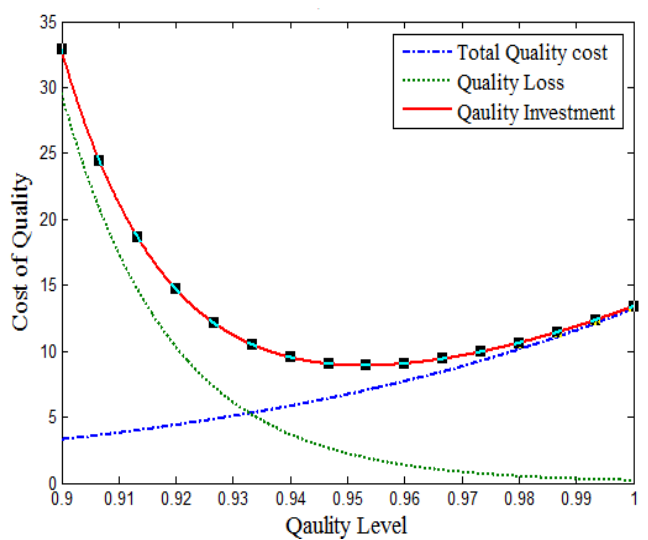

(c) CDF Math Model

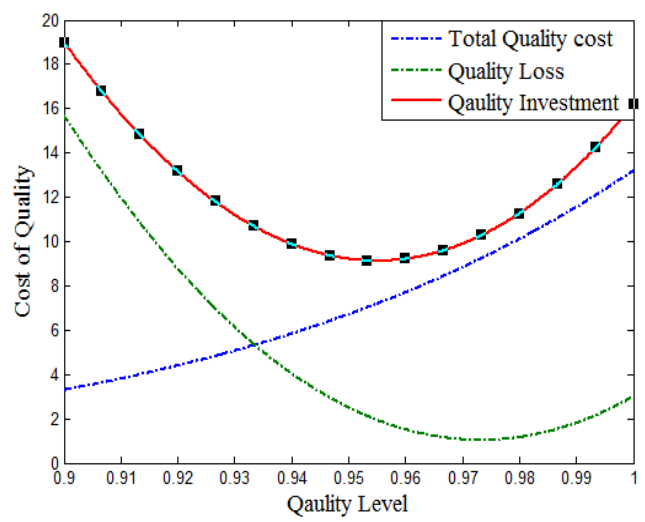

(b) QLF Math Model

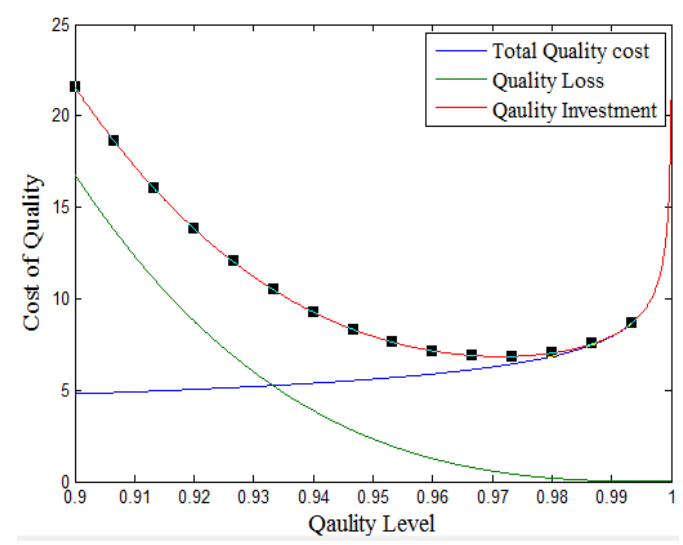

(d) KGM Math Model

\section{Figure 5. The 4 Specific COQ Mathematic Model}

According to the curve fitting procedure, the parameters of QC math models can be estimated as table 4 manifests, as well as the performance index. We can obtain the 4 specific estimated mathematical functions, all of which have excellent fitting performance and operational efficiency.

Table 4. Parameters value

\begin{tabular}{lll}
\hline Items & Parameters value & $r_{N L}$ \\
\hline EF & $W=1.21^{* 1} 0^{-5} e^{13.92 \lambda}+7.09 * 10^{20} e^{-49.69 \lambda}$ & 0.906 \\
QLF & $W=13.15 \lambda^{13.21}+2741 \lambda^{2}-5335 \lambda+2597$ & 0.952 \\
CDF & $W=13.15 \lambda^{13.21} e^{\varepsilon}+0.19 \lambda^{-47.92} e^{\varepsilon}$ & 0.907 \\
KGM & $W=3.02(\lambda / 1-\lambda)^{0.21}+5485(1-\lambda / \lambda)^{2.64}$ & 0.942 \\
\hline
\end{tabular}

On the basis of the four QC math models abovementioned estimated parameters, the optimal quality level and minimum quality cost can be obtained by the following formula (11), and the optimal situation results are presented in Table 5. 


$$
\frac{\partial C O Q}{\partial \lambda}=\frac{\partial Q C}{\partial \lambda}=0
$$

Table 5. Results Presence

\begin{tabular}{lllll}
\hline Items & EF & QLF & CDF & KGM \\
\hline Minimum COQ & 8.7028 & 9.1237 & 8.8982 & 6.8386 \\
Approximate Quality & $95.31 \%$ & $95.51 \%$ & $95.28 \%$ & $97.14 \%$ \\
R/1000@3MIS & 2.19 & 2.02 & 2.23 & 0.82 \\
\hline
\end{tabular}

As we can see from Table 5, the approximate optimal quality level for the four QC models is $0.9531,0.9551,0.9528$, and 0.9714 respectively, all of which show its high standard than 0.903 for food industry researched in the literature. Even though there is some discrepancy for total quality cost item, the relative approximately optimal quality level is about 95\% 97\%. According to the index transformation, the corresponding R/1000@3MIS can be obtained by Eq. (12), and the value of failure frequency index per thousand unit is $2.19,2.02,2.23$, and 0.82 respectively.

$$
R / 1000 @ 3 M I S=\left(1+\lambda^{2}-2 \lambda\right) \times 1000
$$

The first three models argue that it will be economical and cost-effective when the R/1000@3MIS is about 2, while the KGM math model advocates the appropriate quality should be higher than the other three.

\subsection{Potential Cost Saving}

Depending on the four QC math models fitted, all the first three models alert that the optimal and most economical control point is near 2 for R/1000@3MIS, while the fourth KGM model claim that the target point is 0.82 . In order to establish the most appropriate quality level for the organization, the AHP method [30] has been applied into the decision making problem to weight the four different QC math model. According to the investigation and comparison matrix Eq. (13), the weight can be obtained from the established program file utilized by the department of industrial engineering Chongqing University. The relative importance of the four QC math model is $0.13,0.52,0.12$ and 0.23 respectively. From the subjective standpoint of product managers, the first three kinds of COQM show the overwhelming advantages. Thus the target of vehicle quality parameter R/1000@3MIS is 1.79 .

$$
\begin{gathered}
E F, Q L F, C D F, K G M \\
A=Q L L F \\
C D F \\
K G M
\end{gathered} \quad\left[\begin{array}{cccc}
1 & 1 / 3 & 1 & 1 / 2 \\
3 & 1 & 4 & 3 \\
1 & 1 / 4 & 1 & 1 / 2 \\
2 & 1 / 3 & 2 & 1
\end{array}\right]
$$




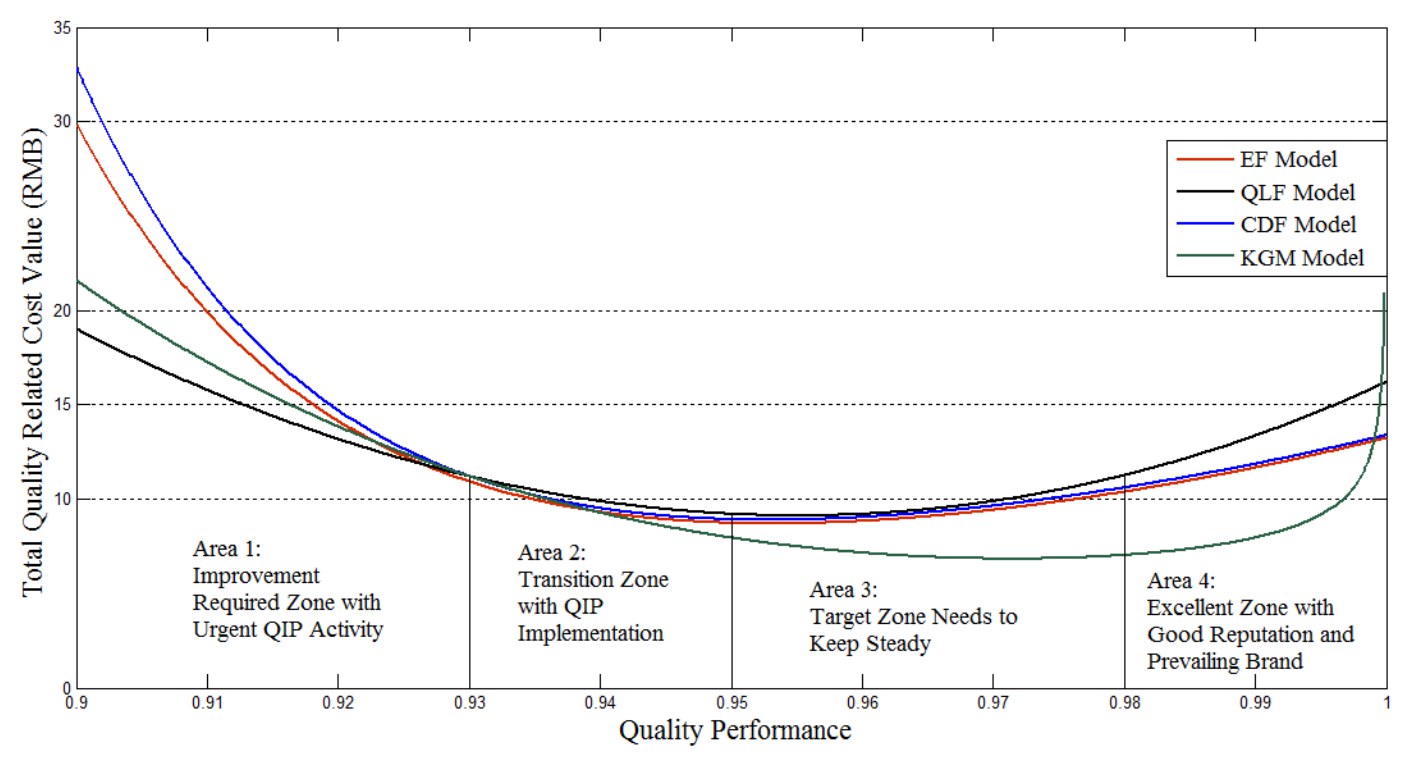

Figure 6. Quality Performance Area Segmentation

As the abovementioned, all of the four cost of quality math model argue their own fitting performance, which assists us to understand the relative optimal quality performance and target R/1000@3MIS. There are several areas for organization or products when during the QIP implementation. According to the COQM model and its quality performance, the four models trade-off between quality cost and quality level has been shown in figure 6 , as well as the scenario area segmented.

The area 1 is low quality performance area whose competitive advantage usually focused on cheap investment such as some industrial factories in bottom of industry chain in China. The area 2 is the transition area whose competitive strategy is towards high quality with relatively low cost, such as the objective CA Corporation, who is engaging in the continuous quality improvement procedure (CQIP). While the most cost-effective situation is whose operations drops into the area 3, which means the effective trade-off between quality-related cost and quality performance. Last, it comes to the area 4 , whose famous strength are more reliable products and higher service quality provision. In practice, there are seldom organizations can arrive in the area 4, especially for Chinese factories, however, there are some elites who can reach the area 3 and obtain a good reputation. It is obvious that the CA Corporation is still in area 2, who struggles to implement the QIP towards to superior quality performance, as well as the brand building. All the four COQM model state that the current quality performance is not enough for brand generation, which needs to implement the continuous quality improvement process whose target is 1.79 for R/1000@3MIS index.

\section{Conclusions}

Quality cost model is the one of the most significant contents of the quality cost management. Traditional quality cost models can help the understanding of the relation between quality cost and quality level. While, there is little organization can identify the quality-related cost, as well as specific COQ mathematical model, even if many firms show much interesting on identification for quality cost.

This paper has studied quality cost category from "conformity+ non-conformity" angle and quality level criteria from statistics perspective for self-brand automotive. Four traditional COQ math models have been verified with empirical study, on the foundation of criteria analysis. Regression analysis based on four function forms has been studied, which makes the conclusion that the four mathematical functions show their particular performance, with the predicable optimal quality level. Results from the estimated COQ 
math models argue that the self-brand engine firms should perform CQIP for quality improvement, instead of low cost investment strategy. The optimal quality performance level has been estimated and the target value of R/1000@3MIS is about 1.79 for quality advancement. The targeted quality performance established by subjective AHP method provides guidance for quality managers on QIP activity and potential cost reduction. In practice, hidden cost due to customer un-satisfaction has not been taken into consideration; consequently the optimal quality level from the case may show its paradox with six sigma theory \& "zero defect" philosophy, which needs for further study.

\section{Acknowledgments}

We appreciate the anonymous referees and the editor for their remarkable comments and manuscript processing. The work is supported by Research Fund for the Doctoral Program of Higher Education (RFDP: 20130191110045); National Key Technology Support Programs (2015BAH46F01 and 2015BAF05B03); Fundamental Research Funds for Central University (106112015CD-JSK02JD05, CDJZR 13110048 and CDJZR 14110001); Chongqing Science \& Technology Research Programs (cstc2015yykfC6002, cstc2015zdcy-ztzx6009 and cstc2014-yykfA40006).

\section{References}

[1] Timans, W.; Ahaus, K.; van Solingen, R.; Kumar, M.; Antony, J., "Implementation of continuous improvement based on Lean Six Sigma in small- and medium-sized enterprises," Total Quality Management \& Business Excellence, vol, no., (2014), pp. 1-16.

[2] Zhou, F.; Wang, X.; Lin, Y.; He, Y.; Zhou, L., "Strategic Part Prioritization for Quality Improvement Practice Using a Hybrid MCDM Framework: A Case Application in an Auto Factory," Sustainability, vol, 8, no. 6, (2016), pp. 559.

[3] Asher, J., "Cost of quality in service industries," International Journal of Quality \& Reliability Management, vol, 5, no. 5, (1988), pp. 38-46.

[4] Schiffauerova, A.; Thomson, V., "A review of research on cost of quality models and best practices," International Journal of Quality \& Reliability Management, vol, 23, no. 6, (2006), pp. 647-669.

[5] Šatanová, A.; Závadský, J.; Sedliačiková, M.; Potkány, M.; Závadská, Z.; Holíková, M., "How Slovak small and medium manufacturing enterprises maintain quality costs: an empirical study and proposal for a suitable model," Total Quality Management \& Business Excellence, vol, no., (2014), pp. 1-15.

[6] Sellés, M. E.; Rubio, J. A.; Mullor, J. R., "Development of a quantification proposal for hidden quality costs: Applied to the construction sector," Journal of Construction Engineering and Management, vol, 134, no. 10, (2008), pp. 749-757.

[7] Uyar, A.; Neyis, A., "Does the healthcare industry report quality costs? Comparative investigations of public and private hospitals," Total Quality Management \& Business Excellence, vol, no., (2014), pp. 1-13.

[8] Khaled Omar, M.; Murgan, S., "An improved model for the cost of quality," International Journal of Quality \& Reliability Management, vol, 31, no. 4, (2014), pp. 395-418.

[9] Williams, A.; Van der Wiele, A.; Dale, B., "Quality costing: a management review," International Journal of Management Reviews, vol, 1, no. 4, (1999), pp. 441-460.

[10] Wang, M.-T.; Wang, S.; Wang, S.; Wang, A. In An Introduction of COQ Models and Their Applications, Proceedings of the 2010 International Conference on Engineering, Project, and Production Management, 2010; 2010.

[11] Vaxevanidis, N.; Petropoulos, G., "A literature survey of cost of quality models," Journal of Engineering, vol, 6, no. 3, (2008), pp. 274-283.

[12] Tsai, W.-H., "Quality cost measurement under activity-based costing," International Journal of Quality \& Reliability Management, vol, 15, no. 7, (1998), pp. 719-752.

[13] Y. ASIEDU, P. G., "Product life cycle cost analysis: state of the art review," International Journal of Production Research, vol, 36, no. 4, (1998), pp.

[14] Zhou, F.; Wang, X.; Wu, N.; Lin, Y.; Ni, L. In Quality cost framework based on lifecycle theory and PAF model, Conference Proceedings of the 4th International Symposium on 
Project Management, ISPM 2016, 2016; Aussino Academic Publishing House: 2016; pp 730735 .

[15] Hwang, G.; Aspinwall, E., "Quality cost models and their application: a review," Total Quality Management, vol, 7, no. 3, (1996), pp. 267-282.

[16] Teli, S.; Majali, V.; Bhushi, U.; Gaikwad, L.; Surange, V., "Cost of Poor Quality Analysis for Automobile Industry: A Case Study," Journal of The Institution of Engineers (India): Series C, vol, 94, no. 4, (2013), pp. 373-384.

[17] Palikhe, H., "A Study of the Cost of Quality for Electric Utility Companies," Texas Tech University, vol, no., (2013), pp.

[18] Chopra, A., "Behavior patterns of quality cost categories," The TQM Magzine, vol, 23, no. 5, (2011), pp. 510-518.

[19] Snieska, V.; Daunoriene, A.; Zekeviciene, A., "Hidden Costs in the Evaluation of Quality Failure Costs," Engineering Economics, vol, 24, no. 3, (2013), pp.

[20] Pires, A. R.; Cociorva, A.; Saraiva, M.; Novas, J. C.; Rosa, Á., "Management of qualityrelated costs. The case of Portuguese companies," Total Quality Management \& Business Excellence, vol, 24, no. 7-8, (2013), pp. 782-796.

[21] Arabian, T.; Jourabchi, S. M.; Leman, Z.; Ismail, M., "A Research on the Impact of Cost of Quality Models and Reporting System on Managing Cost of Quality," International Proceedings of Economics Development and Research, vol, 59, no. 11, (2013), pp.

[22] Lim, C.; Sherali, H. D.; Glickman, T. S., "Cost-of-Quality Optimization via Zero-One Polynomial Programming," IIE Transactions, vol, 47, no. 3, (2014), pp. 258-273.

[23] Naidu, N. V. R., "Mathematical model for quality cost optimization," Robotics and Computer-Integrated Manufacturing, vol, 24, no. 6, (2008), pp. 811-815.

[24] Zugarramurdi, A.; Parin, M. A.; Gadaleta, L.; Lupin, H. M., "A quality cost model for food processing plants," Journal of Food Engineering, vol, 83, no. 3, (2007), pp. 414-421.

[25] Shanshan Shang; Jianxin You, "Model research on the relationship between quality cost and quality level," Statistics and Decision (CN Journal), vol, no. 7, (2010), pp. 72-75.

[26] Madu, C., Handbook of total quality management. Springer Science \& Business Media: 2012.

[27] Guijiang Duan; Yi Yan; Yang Wang, "Analysis and control of quality cost based on data mining," Computer Integrated Manafacturing Systems (CN Journal), vol, 19, no. 07, (2013), pp. 1692-1703.

[28] Ross, S. M., Introduction to probability and statistics for engineers and scientists. Academic press: (2004).

[29] Heravi, G.; Jafari, A., "Cost of Quality Evaluation in Mass-Housing Projects in Developing Countries," Journal of Construction Engineering and Management, vol, 140, no. 5, (2014), pp. 04014004.

[30] Tsai, W.-H.; Hsu, W., "A novel hybrid model based on DEMATEL and ANP for selecting cost of quality model development," Total Quality Management \& Business Excellence, vol, 21, no. 4, (2010), pp. 439-456.

\section{Authors}

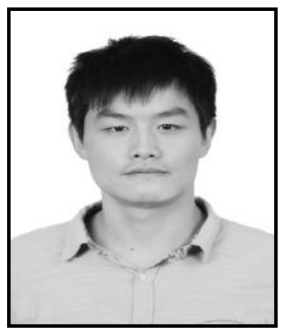

Fuli Zhou, he received the B. Eng. in Industrial Engineering from Henan University of Science \& Technology, Luoyang, China in 2012. Currently, he is attending the master-doctor continuous study and is working toward the $\mathrm{PhD}$ degree in Management Science Engineering at Chongqing University, Chongqing, China. His current research interests include cost of quality, quality management and continuous quality improvement practice.

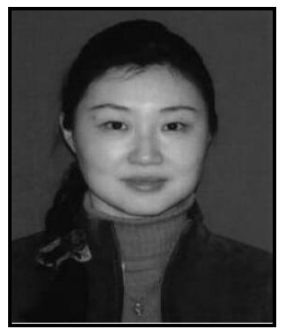

Xu Wang, she received her $\mathrm{BS}$, MS and $\mathrm{PhD}$ degrees in Mechanical Engineering from Chongqing University, China in 1984, 1990 and 2001, respectively. In 2008, she jointed as an expert of modern service industries in the Ministry of Science and Technology. Her research focuses on the total quality management, six sigma, supply chain management and project management etc. 


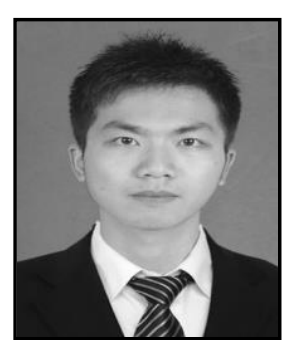

Shan Chen, he received the B. Eng in Industrial Engineering form Southwest Jiaotong University, Chengdu, China in 2013. Currently, he is attending the master-doctor continuous study and is working toward the $\mathrm{PhD}$ degree in Management Science Engineering at Chongqing University, Chongqing, China. His current research interests include total quality management and supply chain management.

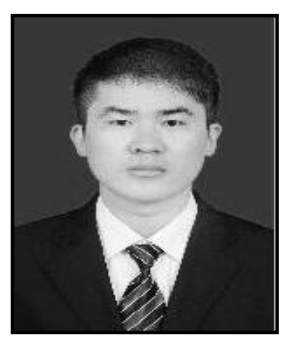

Yandong He, he received his MS degrees in Industrial Engineering from Chongqing University in 2015. Currently, he is pursuing a Doctorate degree in the same department. His research interests include total quality management, decision theory and project management.

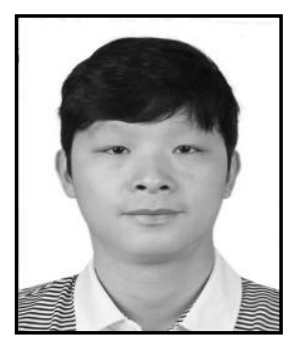

Lin Zhou, he received the B. Eng. degree in Industrial Engineering from Henan University of Science \& Technology, Luoyang, China in 2010. And he receive the M. Eng. degree in Industrial Engineering from Chongqing University, Chongqing, China in 2013. Currently, he is working toward the $\mathrm{PhD}$ degree in Management Science Engineering at Chongqing University, Chongqing, China. And he is participating the joint program in Electrical, Electronic, and Information Engineering at University of Bologna. His current research interests include optimization, algorithms, and logistics. 